\title{
Interleukin-5 and eosinophil cationic protein in nasal lavages of rhinitis patients
}

\author{
Ingrid M. Garrelds ${ }^{a, b, *}$, Tineke De Graaf-in 't Veld ' ${ }^{b}$ Marie-Anne Nahori c , \\ B. Boris Vargaftig ${ }^{c}$, Roy Gerth van Wijk ${ }^{b}$, Freek J. Zijlstra ${ }^{\text {a }}$ \\ a Department of Pharmacology, Faculty of Medicine, Erasmus University Rotterdam, Rotterdam, Netherlands \\ ${ }^{\mathrm{b}}$ Department of Allergology, University Hospital Rotterdam-Dijkzigt, P.O. Box 1738, 3000 DR Rotterdam, Netherlands \\ ${ }^{c}$ Unité de Pharmacologie Cellulaire, Institut Pasteur, 25 Rue du Docteur Roux, 75724 Paris Cedex 15, France
}

Received 23 November 1994; accepted 20 January 1995

\begin{abstract}
The production of interleukin-5 and eosinophil cationic protein (ECP) in the nasal cavity was examined in 24 patients with rhinitis who were allergic to the house dust mite. During a double-blind placebo-controlled cross-over study, fluticasone propionate aqueous nasal spray $(200 \mu \mathrm{g})$ was administered twice daily for 2 weeks. After four basal nasal lavages provocation with house dust mite extract was performed and nasal lavages were collected every hour for 9.5 h. Interleukin-5 was present in detectable amounts in nasal lavages from patients allergic to house dust mite. Nasal challenge with house dust mite extract caused immediate nasal symptoms and increased levels of interleukin-5. Between 3.5 and $8.5 \mathrm{~h}$ after the challenge symptoms recurred and interleukin-5 levels increased, reflecting a late phase reaction. Eosinophil cationic protein, a marker of activated eosinophils, was released between 6.5 and $9.5 \mathrm{~h}$ after challenge. Treatment with fluticasone propionate (as an aqueous nasal spray) significantly decreased the evoked interleukin-5 and ECP levels in the late phase reaction. This response was correlated with an improved symptom score. This could indicate that the number and activity of eosinophils are increased during the late phase allergic reaction, a response that is inhibited by corticosteroids.
\end{abstract}

Keywords: Interleukin-5; Eosinophil cationic protein (ECP); House dust mite; Fluticasone propionate, aquous nasal spray; Rhinitis

\section{Introduction}

Human allergen-induced responses in the nose are used as a model for allergic inflammation (Gerth van Wijk et al., 1992; Naclerio et al., 1983). After provocation with antigen, mediators, such as prostaglandin $\mathrm{D}_{2}$, leukotriene $\mathrm{E}_{4}$, tryptase and histamine, are released during the so-called early allergic reaction, which causes sneezing, nasal blockage and rhinorrhoea. After a quiescent period, a late allergic reaction occurs and symptoms recur (Iliopoulos et al., 1990; Naclerio et al., 1983; Pelikan, 1978). Studies on human nasal late responses have shown an influx of eosinophils and an increase in the content of eosinophil cationic protein

\footnotetext{
* Corresponding author. Department of Pharmacology, Faculty of Medicine, Erasmus University Rotterdam, P.O. Box 1738, 3000 DR Rotterdam, Netherlands. Tel. $(+31) \quad 104087544$, fax $(+31) 10$ 4366839 .
}

(ECP) in nasal fluids $3-11 \mathrm{~h}$ after challenge. The presence of mononuclear cells in lavage fluid during the late responses has also been recognized (Iliopoulos et al., 1990). Several studies have suggested a role for cytokines, particularly granulocyte-macrophage colonystimulating factor (GM-CSF), interleukin-3 and interleukin-5, in the initiation of allergic inflammation. These cytokines promote the survival and activation of eosinophils in vitro, enhance adhesion to microvascular endothelial cells in vitro and induce eosinophilia in vivo. Mosmann and colleagues described two classes of $\mathrm{T}$ helper lymphocytes on the basis of their profile of cytokine release. $T_{H_{1}}$ cells produce interleukin-2, interleukin-3, interferon- $\gamma$ and GM-CSF but no interleukin4 or interleukin-5, whereas $\mathrm{T}_{\mathbf{H} 2}$ clones produce interleukin-3, interleukin-4, interleukin-5, interleukin-10 and GM-CSF but no interleukin-2 or interferon- $\gamma$ (Mosmann et al., 1986). However, the exact cells from which GM-CSF, interleukin-4 and interleukin-5 are 
released remain to be determined, because other studies have shown that mast cells also produce interleukin-4 and interleukin-5 (Wodnar-Filipowicz et al., 1989) whereas eosinophils may produce GM-CSF and interleukin-5.

In our study, the nasal challenge model developed by Naclerio et al. (1983) was used to correlate clinical symptoms and the release of biochemical markers such as interleukin-5 and ECP and to establish whether these markers are formed predominantly in the early or late phase of the allergic process in patients with allergic rhinitis. Furthermore, the effect of fluticasone propionate, a new and potent corticosteroid, on the levels of interleukin-5, ECP and on symptom scores after nasal challenge with allergen was investigated.

\section{Materials and methods}

\subsection{Patients}

This study was performed with 24 patients (11 women and 13 men, aged 21-50 years, mean: 34 years). All patients had a history of perennial rhinitis and a skin reaction to extract of house dust mite as an inclusion criterion. The skin reaction was rated as at least one ' + ' sign in response to 0.3 or 3 biological units (BU) $/ \mathrm{ml}$ extract, according to the standardized plus-sign scoring system. Six of the 24 patients were also allergic to grass pollen or animal dander. The nasal lavage experiments were performed in JanuaryAugust to minimize exposure to house dust mite. The patients with a concomitant pollen allergy were tested outside the pollen season. None of the patients allergic to animals had pets in their home. Anti-histaminic drugs were withdrawn $72 \mathrm{~h}$ before testing. The antihistamine astemizole, topical corticosteroids, cromoglycate or nedocromil were not used for 3 weeks before the start of the study and oral corticosteroids were withdrawn at least 2 months before the study. Patients who developed a nasal infection during the 2-week period prior to the study were excluded. None of the patients had immunotherapy previously.

The study was approved by the Medical Ethics Committee of the University Hospital Rotterdam-Dijkzigt and all patients gave written informed consent.

\subsection{Nasal challenge and lavage}

After the positive skin test the subjects entered the double-blind placebo-controlled cross-over phase of the study. Each underwent two allergen challenges, performed after a twice daily pretreatment with $200 \mu \mathrm{g}$ fluticasone propionate (aqueous nasal spray (Glaxo, UK)) or placebo spray for 2 weeks. A 3-week washout period separated the two treatment periods.

Before nasal challenge with house dust mite extract, a nasal lavage was performed 4 times to obtain baseline levels and to clear the nose of secretions (b). To prevent nasal congestion, $0.25 \mathrm{ml}$ oxymetazoline $(0.1 \%)$ was sprayed into each nostril $5 \mathrm{~min}$ before the first challenge (prescribed by the Hospital Ethical Committee). Nasal lavage was performed as described before (Garrelds et al., 1994; Gerth van Wijk et al., 1992; Naclerio et al., 1983). Both nostrils were washed with 5 $\mathrm{ml}$ saline, prewarmed to $37^{\circ} \mathrm{C}$. Lavage fluid was collected in plastic tubes and kept on ice. After centrifugation $(10 \mathrm{~min}, 400 \times \mathrm{g})$ the supernatants of lavage fluids were stored at $-20^{\circ} \mathrm{C}$ until determinations. Due to the low number of cells in the lavages we were not able to count the number of eosinophils and perform statistical analysis. To obtain a control challenge (c), $0.125 \mathrm{ml}$ phosphate-buffered saline (containing $0.03 \%$ human serum albumin and $0.05 \%$ benzalkonium chloride) was sprayed in each nostril and a nasal lavage was performed. For allergen challenge $0.125 \mathrm{ml}$ allergen extract was sprayed in each nostril and $10 \mathrm{~min}$ thereafter a nasal lavage was performed. Allergen doses of $100,1000,10000(\mathrm{~h} 1-\mathrm{h} 3) \mathrm{BU} / \mathrm{ml}$ (extract of $D$. pteronyssinus; ALK, Groningen, Netherlands) were administered. From $30 \mathrm{~min}$ up to $9.5 \mathrm{~h}$ after the last challenge (given at h3) the nasal washings were collected every hour by washing both nostrils with saline (s1-s10).

\subsection{Symptom score}

Symptoms were scored to assess the correlation between clinical symptoms and interleukin- 5 production. The score was compiled before each lavage and after phosphate-buffered saline challenge and after each allergen spray. Symptom scores were graded in points: $3-4$ sneezes $=1$ point; $\geq 5$ sneezes $=3$ points; rhinorrhoea anterior $=1$ point; rhinorrhoea posterior $=1$ point; difficult nasal breathing $=1$ point; one nostril blocked $=2$ points; both nostrils blocked $=3$ points; pruritus of the nose $=1$ point; pruritus of palate or ear $=1$ point and conjunctivitis $=1$ point (total score ranged from 0 to 11 points).

\subsection{Interleukin-5 assay}

\section{Material}

Tween 20 (Merck, Darmstadt, Germany); bovine serum albumin fraction $\mathrm{V}$ (Euromex, Schiltigheim, France); horseradish peroxidase-conjugated goat antirabbit immunoglobulin $\mathrm{G}$ ( $\mathrm{IgG}) \mathrm{F}\left(\mathrm{ab}^{\prime}\right)_{2}$ (Biosys, Compiègne, France); TMB microwell peroxidase substrate system (Kirkegaard \& Perry Lab., Gaithersburg, MD, USA); polyclonal rabbit anti-human interleukin-5 (Genzyme, Cambridge, MA, USA); anti-human interleukin-5 monoclonal antibody and recombinant human interleukin-5 were kindly provided by Drs. R. Devos and J. Tavernier (Roche, Gent, Belgium). 


\section{Method}

ELISA plates (96-well Immuno Plate MaxiSorp, Nunc, Roskilde, Denmark) were coated with $100 \mu$ l of the anti-human interleukin-5 monoclonal antibody (1 $\mu \mathrm{g} / \mathrm{ml}$ in phosphate-buffered saline, $\mathrm{pH} 7.4$ ) at $37^{\circ} \mathrm{C}$ for $2 \mathrm{~h}$. The wells were washed 5 times with phosphate-buffered saline containing $0.1 \%$ Tween 20 . Then, $100 \mu 1$ of the sample or recombinant human interleukin-5 standard $(0.2-200 \mathrm{ng} / \mathrm{ml})$ in phosphatebuffered saline-Tween and 3\% bovine serum albumin was added to each well and incubated at $37^{\circ} \mathrm{C}$ for $1 \mathrm{~h}$. The wells were washed 3 times with phosphate-buffered saline-Tween and incubated with polyclonal rabbit anti-human interleukin-5 $(10 \mu \mathrm{g} / \mathrm{ml}$ in phosphatebuffered saline-Tween-bovine serum albumin) at $37^{\circ} \mathrm{C}$ for $1 \mathrm{~h}$. After the wells were washed 3 times with phosphate-buffered saline-Tween, horseradish peroxidase-conjugated goat anti-rabbit IgG $\mathrm{F}\left(\mathrm{ab}^{\prime}\right)_{2}$, at a dilution of $1 / 4000$ in phosphate-buffered saline-Tweenbovine serum albumin, was added for $1 \mathrm{~h}$. Then, $100 \mu \mathrm{l}$ of freshly prepared substate solution (TMB microwell peroxidase substate) was added to each well. After a 10 -min incubation, the reaction was stopped by the addition to each well of $100 \mu \mathrm{l}$ of a $2 \mathrm{M}$ solution of $\mathrm{HCl}$. Absorbance was read at $450 \mathrm{~nm}$. The lower limit of sensitivity of the assay was $0.18 \mathrm{ng} / \mathrm{ml}$.

\subsection{Eosinophil cationic protein assay}

ECP was determined in the lavages by radioimmunoassay (Kabi Pharmacia Diagnostics, Uppsala, Sweden).

\subsection{Statistical analysis}

Statistical analysis was performed with the Friedman two-way analysis of variance (ANOVA) followed by the Wilcoxon matched-pairs signed-ranks test. The effect of fluticasone propionate nasal spray on the early phase reaction (area under the curve (AUC) between $\mathrm{h} 1$ and $\mathrm{s} 1$ ) and the late phase reaction (AUC: between $\mathrm{s} 4$ and $\mathrm{s} 10$ ) was assessed. These areas under the curve are based on the outcome of the symptom score. A two-tailed $P$ value $\leq 0.05$ was considered significant.
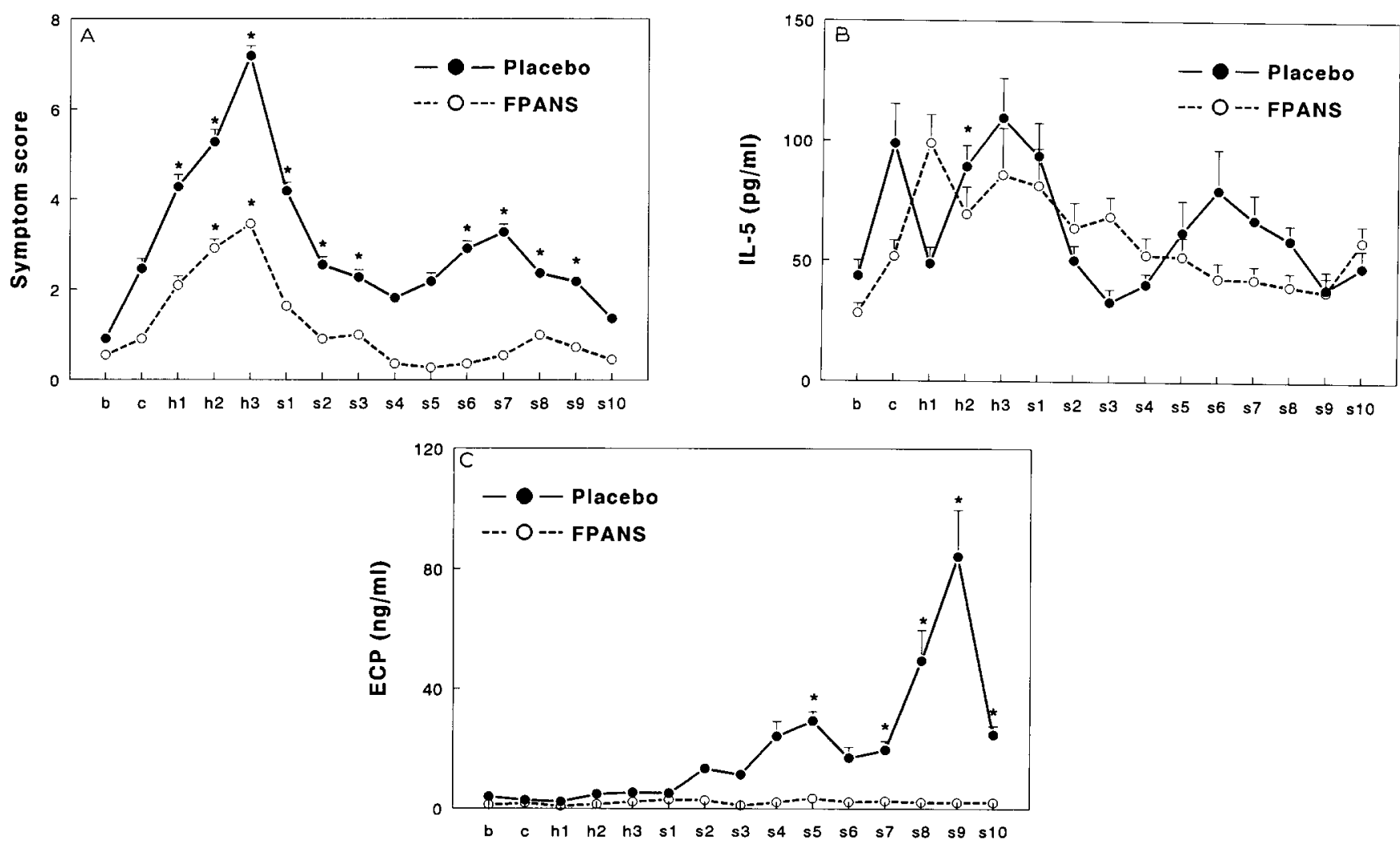

Fig. 1. Effect of placebo $(\bullet)$ and fluticasone propionate aqueous nasal spray $(O)$ on the symptom scores (A), interleukin-5 levels in nasal lavages (B) and eosinophil cationic protein (ECP) levels in nasal lavages (C) of the 11 patients allergic to house dust mite who showed both an early and a late phase reaction. Values are expressed as means \pm S.E.M. Significant differences in comparison to baseline: ${ }^{*} P \leq 0.05$. b: baseline, c: challenge with phosphate-buffered saline; h1, h2 and h3, challenge with 100,1000 and $10000 \mathrm{BU} / \mathrm{ml}$ house dust mite extract respectively; $\mathrm{s} 1-\mathrm{s} 10$, lavage performed every hour after the challenge with $10000 \mathrm{BU} / \mathrm{ml}$ house dust mite extract at $\mathrm{h} 3$. 


\section{Results}

Eleven patients (out of 24) showed both an early and a late phase reaction to the house dust mite extract, as assessed by their symptom scores (Fig. 1A: symptom score; B: interleukin-5; and C: ECP), whereas the other 13 patients showed only an early phase reaction (Fig. 2).

\subsection{Symptom score}

The effects of placebo and fluticasone propionate nasal spray on the symptom scores of the 11 patients who showed both an early and a late phase reaction to the house dust mite with treatment are shown in Fig. 1A. A significant increase was observed immediately after the challenge with house dust mite extract in comparison with baseline levels in the placebo group (h1-s3; $P \leq 0.05$ ) and in the fluticasone group (h2 and h3; $P \leq 0.05$ ). A late phase reaction occurred only in the placebo group, when symptoms recurred (s6-s9; $P \leq 0.05$ ). The symptom score of patients treated with fluticasone propionate nasal spray was significantly lower than that of the placebo group in the early phase reaction (AUC h1-s1; $P \leq 0.05$ ) as well as in the late phase reaction (AUC $\mathrm{s} 4-\mathrm{s} 10 ; P \leq 0.05$ ).

The results of the 13 patients who showed only an early phase reaction are shown in Fig. 2. A significant increase was observed immediately after the challenge with house dust mite extract in comparison with the baseline levels in the placebo group (h1-s1; $P \leq 0.05$ ) and in the fluticasone group (pbs-s3; $P \leq 0.05$ ). No late phase reaction occurred. The symptom score of patients treated with fluticasone propionate nasal spray was significantly lower than that of the placebo group in the early phase reaction (AUC h1-s1; $P \leq 0.05$ ).

\subsection{Nasal interleukin-5 release}

The effects of placebo and fluticasone propionate nasal spray on the levels of interleukin-5 in nasal washings from the 11 patients with both an early and a late phase allergic reaction to house dust mite are presented in Fig. 1B. Interleukin-5 levels varied between 50 and $100 \mathrm{pg} / \mathrm{ml}$ before provocation, with a tendency towards an increase in comparison with the baseline level in the placebo group (h2; $P=0.0702$ ), a tendency which was not seen in the fluticasone propionate group. During the late phase reaction interleukin-5 was released again in the placebo group. Fluticasone propionate nasal spray significantly inhibited the release of interleukin- 5 in the late phase reaction in comparison with placebo (AUC s4-s10; $P \leq 0.05$ ).

The 13 patients with only an early phase allergic reaction to house dust mite who were treated with
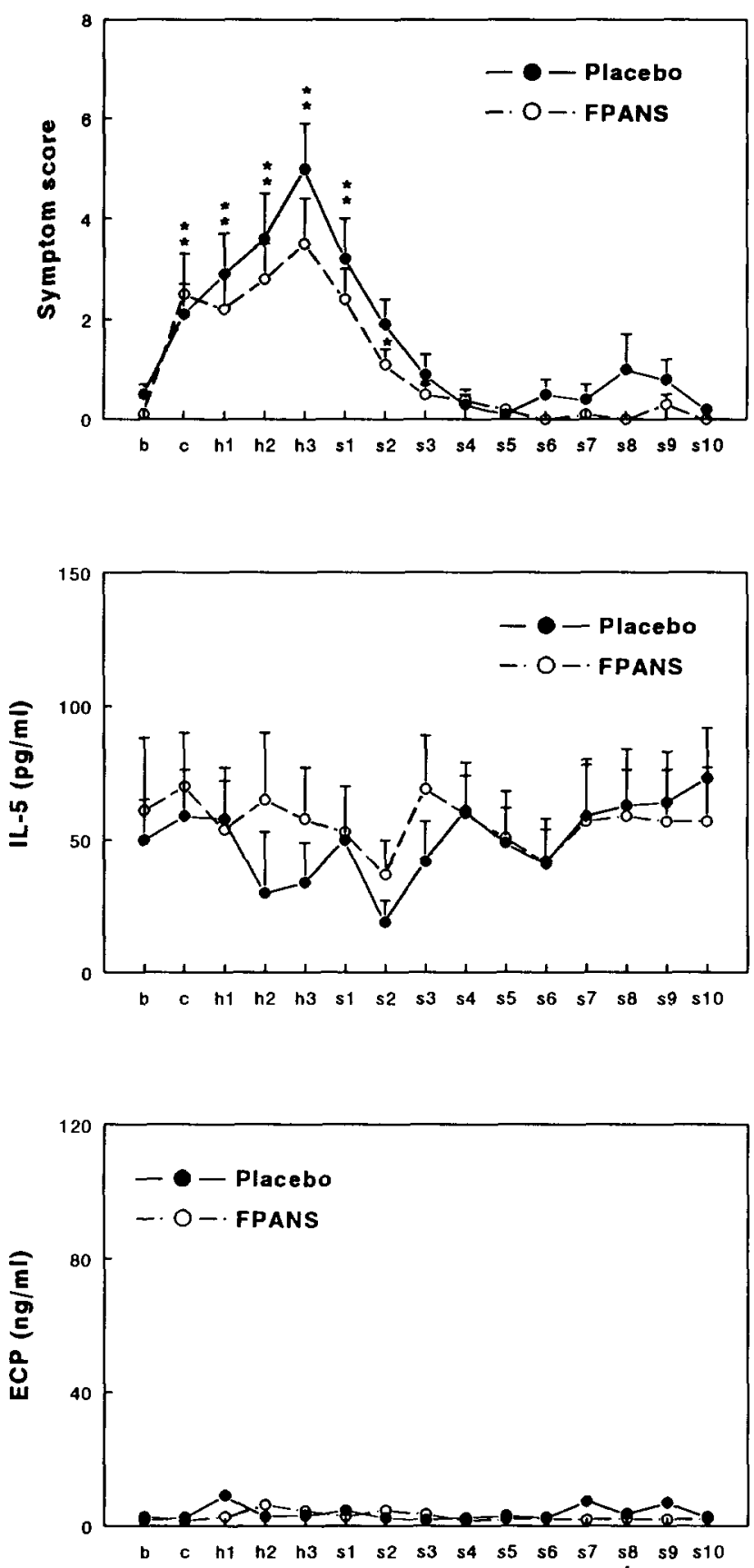

Fig. 2. Effect of placebo (•) and fluticasone propionate aqueous nasal spray $(O)$ on the symptom scores, and interleukin-5 and eosinophil cationic protein levels in nasal lavages of the 13 allergic patients to house dust mite who showed only an early phase reaction. Values are expressed as means \pm S.E.M. Significant differences in comparison to baseline: ${ }^{*} P \leq 0.05$. b: baseline, $c$ : challenge with phosphate-buffered saline; h1, h2 and h3, challenge with 100,1000 and $10000 \mathrm{BU} / \mathrm{ml}$ house dust mite extract respectively; $\mathrm{s} 1-\mathrm{s} 10$, lavages performed every hour after the challenge with $10000 \mathrm{BU} / \mathrm{ml}$ house dust mite extract at $\mathbf{h} 3$.

placebo or fluticasone propionate nasal spray showed neither an immediate nor a late phase release of interleukin-5 (Fig. 2). 


\subsection{Eosinophil cationic protein}

The effects of placebo and fluticasone propionate nasal spray on the ECP levels of the 11 patients who showed both an early and a late phase reaction to house dust mite are shown in Fig. 1C. A significant increase in ECP was observed in comparison with the baseline levels during the late phase reaction (s7-s10; $P \leq 0.05$ ). The ECP level in nasal lavages was significantly decreased by treatment with fluticasone propionate nasal spray in comparison with those of the placebo during the late phase (AUC $s 4-\mathrm{s} 10 ; P \leq 0.05$ ) (De Graaf-in 't Veld et al., 1995).

The 13 patients with only an early phase allergic reaction to house dust mite did not show a late phase release of ECP (all levels were below $10 \mathrm{ng} / \mathrm{ml}$; Fig. 2) after placebo or fluticasone propionate.

\section{Discussion}

This is the first study demonstrating that interleukin-5 is present in detectable amounts in nasal lavage obtained from patients allergic to house dust mites who show both an early and late phase reaction. Nasal challenge with house dust mite extract immediately caused nasal symptoms and tended to increase levels of interleukin-5 in the placebo group in the early phase reaction. Nasal challenge with phosphatebuffered saline also caused an immediate increase in the level of interleukin-5 in the placebo group, which may indicate a nonspecific reaction due to the human serum albumin in the phosphate-buffered saline. Between 3.5 and $8.5 \mathrm{~h}$ after the challenge with house dust mite extract symptoms recurred and interleukin-5 levels increased, reflecting a late phase reaction.

Interleukin-5 was released in the lungs of rhinitis patients allergic to ragweed $24 \mathrm{~h}$ after segmental antigen challenge, and this release correlated with eosinophil recruitment, degranulation, and lung injury (Ohnishi et al., 1993). In inferior turbinate biopsies from patients with perennial allergic rhinitis interleukin-4 and interleukin-5 were localized by immunohistochemical staining of mast cells and interleukin-5 immunoreactivity was also localized in eosinophils. No immunoreactivity for cytokines was found in $\mathrm{T}$ cells (Bradding et al., 1993). In studies with grass pollensensitive patients $24 \mathrm{~h}$ after local provocation with antigen, nasal biopsies showed an increase in cells with positive mRNA hybridization signals for interleukin-3, interleukin-4, GM-CSF and interleukin-5 (Durham et al., 1992) when allergen-challenged sites were compared with control sites. It has been recently demonstrated by Terada et al. that interleukin- 5 is released in nasal fluid in the late phase reaction after challenge with Japanese cedar (Terada et al., 1994).

In this study we demonstrated that ECP was re- leased a few hours later (between 6.5 and $9.5 \mathrm{~h}$ ) than interleukin-5 (between 3.5 and $8.5 \mathrm{~h}$ ), which may indicate that the number of eosinophils was increased and/or that the eosinophils present were more activated during the late allergic reaction. Due to the low numbers of cells in the lavages we were not able to perform statistical analysis of eosinophil numbers.

Our study showed a significant decrease in interleukin-5 and ECP levels during the late phase reaction after treatment with fluticasone propionate nasal spray. This decrease correlated with an improved symptom score in the 11 patients with an early and late phase reaction. A decreased release of ECP may indicate that the number of eosinophils was decreased and/or that the eosinophils were less active during the late allergic reaction after treatment with fluticasone propionate nasal spray. The protective effects of fluticasone propionate nasal spray on interleukin-5 were detected in the late phase reaction and failed to affect the initial (baseline) release of interleukin-5 as well as the early phase response to house dust mite provocation. Other factors involved in allergic rhinitis, such as albumin, tryptase, leukotriene $\mathrm{E}_{4}$, prostaglandin $\mathrm{D}_{2}$ and platelet activating factor, are also increased after house dust mite provocation and are inhibited by fluticasone propionate nasal spray (Garrelds et al., 1994; De Graaf-in 't Veld et al., 1995).

Pretreatment with fluticasone propionate nasal spray improved the symptom score of patients with seasonal allergic rhinitis after nasal challenge with allergen and decreases the number of nasal eosinophils, basophils and neutrophils (Juliusson et al., 1993). It has been proposed that fluticasone propionate nasal spray may act by preventing the activation of these cells and the subsequent release of (chemotactic) inflammatory mediators and further influx of cells. Several in vitro studies have shown that corticosteroids inhibit $\mathrm{T}$ cell proliferation and cytokine production (Culpepper and Lee, 1985), decrease the number of cells expressing interleukin-4 and interleukin-5 mRNA in vivo (Robinson et al., 1993) and decrease the number and activation of mast cells and eosinophils in bronchial biopsies and lavages (Djukanovic et al., 1992).

In summary, the results of this study show that interleukin-5 was found in detectable amounts in nasal lavages of patients with a house dust mite allergy before and after challenge with house dust mite extract, which caused immediately nasal symptoms. Between 3.5 and $8.5 \mathrm{~h}$ after the last challenge symptoms recurred and interleukin-5 levels increased, reflecting a late phase reaction. ECP was released between 6.5 and $9.5 \mathrm{~h}$ after challenge. A 2-week pretreatment with 200 $\mu \mathrm{g}$ fluticasone propionate aquous nasal spray resulted in a significant decrease in interleukin-5 and ECP levels in the late phase reaction. This decrease was correlated with an improved symptom score. 
Although it is not fully understood how the mechanism of interleukin-5 release is modulated, the programmed release of this cytokine would be of interest in other allergic reactions.

\section{Acknowledgements}

This study was supported by Glaxo BV, Netherlands and by the Netherlands Asthma Foundation, Grant 32.92.74. Fluticasone propionate aqueous nasal spray was given by Glaxo.

Nasal challenges and lavages were performed at the Department of Allergology and the measurements at the Department of Pharmacology, Erasmus University Rotterdam, Netherlands and the Department of Pharmacologie Cellulaire, Institute Pasteur, France.

\section{References}

Bradding, P., I.H. Feather, S. Wilson, P.G. Bardin, C.H. Heusser, S.T. Holgate and P.H. Howarth, 1993, Immunolocalization of cytokines in the nasal mucosa of normal and perennial rhinitic subjects, J. Immunol. 151, 3853.

Culpepper, J.A. and F. Lee, 1985, Regulation of interleukin-3 expression by glucocorticoids in cloned murine $\mathrm{T}$ lymphocytes, $\mathrm{J}$. Immunol. 135, 3191.

De Graaf-in 't Veld, C., I.M. Garrelds, A.P.H. Jansen, A.W. Van Toorenenbergen, P.G.H. Mulder, J. Meeuwis and R. Gerth van Wijk, 1995, Effect of intranasal fluticasone propionate on the immediate and late allergic nasal reaction and nasal hyperreactivity in patients with a house dust mite allergy, Clin. Exp. Allergy (in press).

Djukanovic, R., J.W. Wilson, K.M. Britten, S.J. Wilson, A.F. Walls, W.R. Roche, P.H. Howarth and S.T. Holgate, 1992, Effect of inhaled corticosteroid on airway inflammation and symptoms in asthma, Am. Rev. Respir. Dis. 145, 669.

Durham, S.R., S. Ying, V.A. Varney, M.R. Jacobson, R.M. Sudderick, I.S. Mackay, A.B. Kay and Q.A. Hamid, 1992, Cytokine messenger RNA expression for interleukin-3, interleukin-4, interleukin-5 and granulocyte/macrophage-colony-stimulating factor in the nasal mucosa after local allergen provocation: relationship to tissue eosinophilia, J. Immunol. 148, 2390.

Garrelds, I.M., T. De Graaf-in 't Veld, A.P.H. Jansen, R. Gerth van Wijk and F.J. Zijlstra, 1994, Effect of fluticasone propionate aquous nasal spray treatment on platelet activating factor and eicosanoid production by nasal mucosa in patients with a house dust mite allergy, Mediators Inflamm. 3, 381.

Gerth van Wijk, R., F.J. Zijlstra, A.W. Van Toorenenbergen, A. Vermeulen and P.H. Dieges, 1992, An isolated early response after nasal allergen challenge is sufficient to induce nasal hyperreactivity, Ann. Allergy 69, 43.

Iliopoulos, O., D. Proud, N.F. Adkinson, P.S. Norman, A. KageySobotka, L.M. Lichtenstein and R.M. Naclerio, 1990, Relationship between the early, late and rechallenge reaction to nasal challenge with antigen: observations on the role of inflammatory mediators and cells, J. Allergy Clin. Immunol. 86, 851.

Juliusson, S., K. Holmberg, G. Karlsson, L. Enerback and U. Pipkorn, 1993, Mast cells and mediators in the nasal mucosa after allergen challenge. Effects of four weeks' treatment with topical glucocorticoid, Clin. Exp. Allergy 23, 591.

Mosmann, T.R., H. Cherwinski, M.W. Bond, M.A. Gieldin and R.L. Coffman, 1986, Two types of murine helper $\mathrm{T}$ cell clone, J. Immunol. 136, 2348.

Naclerio, R.M., H.L. Meier, A. Kagey-Sobotka, N.F. Adkinson, Jr., D.A. Meyers, P.S. Norman and L.M. Lichtenstein, 1983, Mediator release after nasal airway challenge with allergen, Am. Rev. Respir. Dis. 128, 597.

Ohnishi, T., S. Sur, D.S. Collins, J.E. Fish, G.J. Gleich and S.P. Peters, 1993, Eosinophil survival activity identified as interleukin-5 is associated with eosinophil recruitment and degranulation and lung injury twenty-four hours after segmental antigen lung challenge, J. Allergy Clin. Immunol. 92, 607.

Pelikan, Z., 1978, Late and delayed responses of the nasal mucosa to allergen challenge, Ann. Allergy 41, 37.

Robinson, D.S., Q. Hamid, A.M. Bentley, Sun Ying, A.B. Kay and S.R. Durham, 1993, Activation of $\mathrm{CD}^{+} \mathrm{T}$ cells, increased $\mathrm{T}_{\mathrm{H}^{-}}$ type cytokine mRNA expression, and eosinophil recruitment in bronchoalveolar lavage after allergen inhalation challenge in patients with atopic asthma, J. Allergy Clin. Immunol. 92, 313.

Terada, N., A. Konno, S. Fukuda, T. Yamashita, K. Shirotori, Y. Okamoto, K. Ishikawa and K. Togawa, 1994, Interleukin-5 gene expression in nasal mucosa and changes in amount of interleukin-5 in nasal lavage fluid after antigen challenge, Acta Otolaryngol. (Stockh.) 114, 203.

Wodnar-Filipowicz, A., C.H. Heusser and C. Moroni, 1989, Production of the haemopoietic growth factors GM-CSF and interleukin-3 by mast cells in response to IgE receptor mediated activation, Nature 339, 150. 